\title{
GUARDA COMPARTILHADA NO BRASIL E NO URUGUAI: TENSÕES NA INSTITUIÇÃO DA IGUALDADE PARENTAL
}

Carolina de Campos Borges

Universidade Federal da Grande Dourados

Anna Paula Uziel

Universidade do Estado do Rio de Janeiro

Edna Lúcia Tinoco Ponciano

Universidade do Estado do Rio de Janeiro

\begin{abstract}
Resumo
Este trabalho consiste em um estudo teórico-documental realizado como parte de uma pesquisa mais ampla, ainda em andamento, que investiga as relações parentais na guarda compartilhada no Brasil e no Uruguai. Buscou-se compreender como, histórica e juridicamente, a guarda compartilhada foi instituída nesses países e discutir a relação entre sua instituição e igualdade parental, tendo em conta os processos sociais envolvidos na determinação da igualdade entre homens e mulheres. Os resultados apontaram que, no Uruguai, a instituição da guarda compartilhada derivou de direitos adquiridos pelas mulheres enquanto, no Brasil, foi consequência da mobilização de pais, reivindicando seus direitos frente às mães de seus filhos. Em consequência das diferentes posições ocupadas por homens e mulheres na sociedade, a guarda compartilhada é apreendida por eles como lutas distintas. Concluiu-se que, nos dois países, sua instituição representa avanços em prol da convivência familiar, mas não é suficiente para promover a igualdade parental.
\end{abstract}

Palavras-chave: guarda compartilhada; parentalidade; gênero; Brasil; Uruguai.

\section{SHARED CUSTODY AT BRAZIL AND URUGUAY: TENSIONS IN THE INSTITUTION OF PARENTAL EQUALITY}

\begin{abstract}
This work consists in a theoretical-documentary study performed as a part of a wider research, still in progress, that investigates the parental relationships in shared custody both in Brazil and in Uruguay. We aimed to comprehend how, historically and legally, shared custody was instituted in these countries and discuss the relationship between their institution and parental equality, taking into account the social processes involved in determining equality between men and women. The results showed that in Uruguay, the institution of shared custody derived from rights acquired by women, while in Brazil it was a consequence of the mobilization of fathers, claiming their rights towards the mothers of their children. Because of the different positions held by men and women in society, they perceive shared custody as distinct struggles. We concluded that, in both countries, their institution represents advances in favor of family acquaintanceship, but is not enough to promote parental equality.
\end{abstract}

Keywords: shared custody; parenting; gender; Brazil; Uruguay.

\section{CUSTODIA COMPARTIDA EN BRASIL Y URUGUAY: TENSIONES EN LA INSTITUCIÓN DE LA IGUALDAD PARENTAL}

\section{Resumen}

Este trabajo consiste en un estudio teórico y documental realizado como parte de una 
investigación más amplia, aún en progreso, que investiga las relaciones familiares en custodia compartida tanto en Brasil como en Uruguay. El objetivo fue comprender cómo, histórica y legalmente, se instituyó la custodia compartida en estos países y discutir la relación entre su institución e igualdad parental, teniendo en cuenta los procesos sociales involucrados en la determinación de la igualdad entre hombres y mujeres. Los resultados mostraron que, en Uruguay, la institución de la custodia compartida derivó de los derechos adquiridos por las mujeres, mientras que, en Brasil, fue una consecuencia de la movilización de los padres, reclamando sus derechos hacia las madres de sus hijos. Como resultado de las diferentes posiciones de hombres y mujeres en la sociedad, la custodia compartida es percibida por ellos como luchas distintas. Concluimos que, en ambos países, su institución representa avances a favor de la convivencia familiar, pero no es suficiente para promover la igualdad parental.

Palabras clave: custodia compartida; parentalidad; género; Brasil; Uruguay.

\section{INTRODUÇÃO}

Compreender como, histórica e juridicamente, a guarda compartilhada foi instituída no Brasil e no Uruguai e, a partir do panorama traçado, discutir a relação entre sua instituição e a igualdade parental, tendo em conta os processos sociais envolvidos na determinação da igualdade entre homens e mulheres, é a proposta deste artigo. Consiste em um estudo teórico-documental realizado como parte de uma pesquisa mais ampla, ainda em andamento, cujo objetivo é investigar as relações parentais estabelecidas por pais e mães brasileiros e uruguaios, separados e que compartilham a guarda dos filhos.

Neste estudo, ponderamos o fato de haver diferenças na forma como a lei alcança as diferentes classes sociais, mesmo que ela seja universal, sobretudo em países muito marcados pela desigualdade social. Consideramos que uma discussão sobre a lei de guarda compartilhada, embora diga respeito a toda a população, possivelmente esteja mais presente no cotidiano de pessoas de certos extratos sociais, que dispõem de bens e benefícios e que, geralmente, buscam uma regulação formal das relações. Dito isso, até o final do texto, vamos nos referir muito mais a este segmento, sem que o pontuemos a cada momento.

A guarda compartilhada tem sido instituída em vários países, como Inglaterra, França, Canadá, Estados Unidos, e também Uruguai, Argentina e Cuba, há algumas décadas, como uma forma de amenizar o sofrimento que, geralmente, a separação dos pais traz para os filhos, sobretudo aquele decorrente do afastamento de um dos dois, em geral do pai, muito frequente nos regimes de guarda unilateral. Espera-se, também, que a guarda compartilhada ajude a tornar mais igualitárias as relações parentais, nos casos em que os pais não vivem juntos, responsabilizando ambos pela criação dos filhos e criando um cotidiano onde eles estejam mais presentes (Côté, 2016; Daltro Filho, 2014; Grisard Filho, 2014; Prado, \& Barros, 2016; Silva, 2008).

A recomendação do exercício conjunto da autoridade parental por pais e mães reflete mudanças de paradigma no campo do Direito. Um ponto inicial dessa mudança pode ser considerado o reconhecimento da igualdade entre os indivíduos, cujo marco se estabeleceu com a Declaração dos Direitos dos 
Homens de 1879, onde se afirmou que "Os homens nascem e morrem livres e iguais em direitos. São direitos imprescindíveis do homem a liberdade, a propriedade, a segurança e a resistência à opressão" (Dumont, 1983, p. 121). Não se tratava, naquele momento, de reivindicar a igualdade de direitos entre homens e mulheres, mas de estabelecer a igualdade como valor fundamental na configuração social moderna.

O princípio da igualdade impulsionou, conforme Dumont (1983), a individualização da sociedade, demarcando a origem jurídica de uma concepção de indivíduo livre, autônomo, possuidor de interioridade, profundidade e singularidade, compondo o delineamento de uma nova configuração de valores sociais e psicológicos (Dumont, 1983; Simmel, 1989; Singly, 2007). Em consequência disso, atualmente, há um entendimento de que essas sociedades devem promover o pleno desenvolvimento do ser humano, preservando-o de qualquer constrangimento que possa impedir sua existência plena (Dumont, 1983).

Este é um posicionamento que exprime a especificidade do laço social contemporâneo, no qual, conforme de Singly (2005; 2007), o indivíduo ocupa a centralidade na vida social. Nesse contexto, cada um é livre para escolher a forma de vida que deseja, e a vida privada se estrutura, sobretudo, pelo reconhecimento mútuo de pessoas que se concebem como significativas, que vivem juntas e se respeitam.

De Singly (2005) considera que o "eu" contemporâneo, a identidade individualizada, constrói-se principalmente em um diálogo interior, que os indivíduos estabelecem consigo mesmo por intermédio das pessoas significativas. Assim, cada indivíduo precisa de pessoas que saibam reconhecer nele alguma coisa de autêntica ou especial, que tenham um olhar pessoal capaz de ver além das aparências associadas a posições sociais, à lógica de pertencimento a grupos ou a outros estatutos, de modo que as relações afetivas são requeridas para propiciar que o "eu" se descubra.

Nesse contexto, a família é entendida como uma rede de relações de intimidade, possuindo um papel muito importante para a constituição da identidade pessoal. Considera-se que a família contemporânea, comumente espaço de relações afetivas, pessoais e duráveis, além de contribuir para a reprodução biológica e social da sociedade, tem a função de "revelação de si", nas palavras de Singly (2005). Ela é o lugar onde, em geral, as pessoas, sejam homens ou mulheres, crianças, jovens ou adultos, elaboram esta forma de interioridade, concebendo-se como seres dotados de profundidade íntima e criando o sentimento de autenticidade do eu.

Tal perspectiva reflete na forma como as relações familiares são concebidas nas leis. Como explica Simão (2005), o Direito Civil Brasileiro e de muitos países do ocidente tem se comprometido com a proteção dos direitos inerentes à personalidade e com as circunstâncias necessárias para sua 
realização, não mais se detendo sobre a proteção da propriedade. Em consequência disso, todos os indivíduos, incluindo crianças, adolescentes e idosos, se destacaram como sujeito de direitos e de proteção do estado e a família foi incorporada às leis como palco de manifestação de afetos e de realização de seus integrantes.

Neste novo espírito, sendo amplamente reconhecida a importância das relações familiares para a saúde e o desenvolvimento dos indivíduos, os textos das leis passaram a enfatizar a importância da responsabilidade dos pais e das mães para a formação dos filhos (Ponciano \& Féres-Carneiro, 2017). Por isso, mesmo que a família não seja sempre este locus inicial de afeto, suas relações são reguladas pelo Estado em alguns casos, como quando há o rompimento das relações conjugais.

Assim, em meio à valorização dos indivíduos e das relações familiares, emerge a lei que regulamenta a guarda compartilhada e assegura o direito de pais, mães e filhos ao convívio, quando não vivem sob o mesmo teto. Conforme Leite (2003), a responsabilização conjunta do pai e da mãe pela criação de seus filhos e, assim, o exercício conjunto de seus direitos e deveres, é uma estratégia para se evitar os prejuízos que o divórcio ou a separação geralmente trazem para o desenvolvimento de crianças e adolescentes. Ou melhor, para se prevenir as consequências advindas da ausência e do distanciamento sentidos pelos filhos em relação àquele/a que, nos casos de um regime unilateral, não detém sua guarda, como ressalta Silva (2005).

A convivência familiar se constrói durante o tempo em que pai e filhos ou mãe e filhos estão juntos. Quando o convívio não existe, ou quando ele ocorre em intervalos irregulares e espaçados de tempo, normalmente a imagem que o filho constrói daquele que não detém a guarda é formada com a interferência de quem a detém, ficando, muitas vezes, marcada por sentimentos de rancor que acompanham as desavenças conjugais. Por isso, é suposto que a guarda compartilhada, propiciando uma convivência mais próxima entre pai-filhos e mãe-filhos, sem privilegiar um lado ou outro nas decisões sobre eles, promova melhores condições de vida, evitando o desgaste e o sofrimento decorrente do distanciamento de algum dos pais ou até mesmo que sejam abandonados pelos seus responsáveis (Cardoso, 2006; Silva, 2005; Sottomayor, 2014).

Além da preocupação com as crianças e adolescentes, numa clara referência à valorização social da afetividade, a instituição da guarda compartilhada está relacionada à afirmação do princípio da igualdade social. Ela promove, conforme Montaño (2016), o igualitarismo nas relações parentais, propiciando uma reorganização dos papéis de gênero na família e na sociedade, favorecendo a superação de um modelo de organização familiar baseada na distinção rígida entre os papéis de pai e mãe, na qual caberia ao pai o sustento da prole e à mãe, o cuidado, a educação e o afeto. 
A associação da mulher com a maternidade (ato de gerar um filho) e a maternagem (ato de cuidar do filho), e, por consequência, sua valorização como figura fundamental no cuidado dos filhos, decorre de processos históricos e sociais vividos desde o século XVII, na Europa - processos esses que corroboraram para a constituição do modelo da família conjugal moderna, que influenciou todo o ocidente. Como explicam Ariès (2006), Prost e Vincent (1999) e Lash (1991), mediante o progressivo fechamento da vida privada aos assuntos e atividades do mundo público, gerado pela escolarização das crianças e pela industrialização da sociedade, foi introduzida uma carga afetiva às relações estabelecidas na família, marcando especialmente a relação das mulheres com seus filhos, já que eram elas que, geralmente, cuidavam da vida nos limites domésticos.

Isso tudo culminou na naturalização de uma imagem da mulher como alguém essencialmente delicada e propícia aos cuidados do lar e contribui para que se constitua um discurso sobre o amor materno, que o define como instintivo e, portanto, próprio às mulheres. Ora, como explicam Beauvoir (1980) e Badinter (1998), o amor de uma mãe por seus filhos não é determinado pela natureza e sim construído, socialmente, como qualquer outro amor. Visto desta maneira, desconstrói-se a ideia de naturalidade ou superioridade do amor materno em relação ao amor paterno e, ainda, sua necessária existência.

A alusão à mãe como alguém naturalmente boa, abnegada, propícia a cuidar dos outros, alimenta outro discurso, também tradicional, sobre o homem definido como alguém forte, racional, pouco apto às atividades da vida doméstica, mais propício aos assuntos do mundo público. Sobretudo na América Latina e no Brasil, nas diversas classes sociais, segundo Rocha-Coutinho (2000), os homens são tradicionalmente descritos como "machistas", "viris", e incorporam essas características como sinônimo de masculinidade. Daí o fato de serem geralmente vistos como provedores financeiros de sua família, mais voltados às incumbências do mundo público e, por isso, menos capazes do que as mulheres de assumirem a guarda de seus filhos. Vale ressaltar que isso traz variadas consequências para eles e elas, sobretudo em um mundo capitalístico com relações de trabalho cada vez mais precarizadas e com um desemprego crescente, onde esta mesma desigualdade de gênero mantém as mulheres no mercado informal de trabalho e tira dos homens a possibilidade de prover sua família.

Desta forma, a ideia de que pais e mães podem dividir igualmente suas responsabilidades na criação dos filhos impulsiona a desmistificação da figura materna como a mais propícia ao cuidado e inaugura uma nova imagem social paterna: a de alguém que também pode se envolver com os assuntos domésticos (Montaño, 2016). Constitui-se, assim, um novo perfil para pais, dispostos a exercer a paternidade de uma forma mais próxima e íntima de seus filhos, o que é cada vez mais evidente nas novas gerações, fazendo da 
redescoberta do amor paterno, como afirma Leite (2003), ou da invenção do amor paterno, se preferir, uma das mudanças de maior impacto na questão da responsabilidade parental.

Nesse cenário, o esperado é que a instituição da guarda compartilhada contribua para corrigir uma desigualdade produzida por um padrão tradicional de guarda única, na qual, geralmente, reconhece-se a figura da mãe como a pessoa mais propícia a receber a guarda dos filhos e exclui-se da vida das crianças o pai, não reconhecendo sua importância para o desenvolvimento delas - e, tampouco, a importância de um filho na vida de um pai (Silva, 2011). No entanto, pode-se questionar se ela realmente cumpre esta expectativa, produzindo uma mudança profunda no padrão de relação parental estabelecido entre homens e mulheres e traduzindo-se em igualdade de gênero nas relações. Que tensões se apresentam nessa tentativa de estabelecimento da igualdade parental? Qual a importância da legislação nesse processo de produção de equidade?

Para discutir essas questões, é apresentado um estudo teórico-documental realizado sobre o processo de regulamentação da guarda compartilhada no Uruguai e no Brasil. Optou-se por pesquisar em dois países, considerando que esta perspectiva permite uma compreensão acerca de especificidades históricas envolvidas no processo investigado, neste caso o processo de instituição da guarda compartilhada, que força a suspensão de naturalizações ancoradas na cultura pelo pesquisador, como discute Nardi (2008). Ademais, é interessante, pois a necessidade de se fazer a imersão em uma nova cultura e em uma nova língua leva o pesquisador a um estranhamento duplo - em relação à cultura diferente que se pretende compreender e, também, em relação ao conhecimento que se pressupunha ter a partir das hipóteses com as quais se vinha trabalhando na sua própria cultura - o que é muito frutífero. Esse processo favorece a desnaturalização de práticas e pré-noções, sendo uma ferramenta que propicia a produção de um conhecimento muito interessante (Nardi, 2008).

A escolha por se trabalhar com o Uruguai e o Brasil, especificamente, ocorreu por se considerar que suas realidades sociais, embora sejam distintas em muitos aspectos, são próximas e, portanto, comparáveis. Consistem em países pertencentes à América do Sul, que sofrem os efeitos de uma colonização europeia na sua constituição social, mas que viveram diferentemente seu processo de independência, de democratização e, claro, de instituição da guarda compartilhada. Esta conjuntura propicia a apreensão de certas nuances que influenciam diretamente o processo de regulamentação da guarda compartilhada - a saber, a ascensão dos direitos das mulheres e dos homens e as mudanças geradas, em torno das relações de gênero, nas relações parentais. Por isso, considera-se esta uma oportunidade ímpar de se apreender o terreno da instituição da guarda compartilhada como uma arena onde se confrontam interesses de homens e de mulheres, em uma disputa por território e poder, 
revelando as tensões subjacentes ao processo de instituição da igualdade parental, que vem sendo conquistada legalmente, nos últimos anos.

Igualdade de gênero inscreve-se como algo importante em uma sociedade alicerçada em valores igualitários. O projeto de uma sociedade igualitária fundase, de acordo com Dumont (1983) e Simmel (1989), no reconhecimento da condição de igualdade dos indivíduos, sendo esta entendida como igualdade quantitativa, referente à igualdade social, e igualdade qualitativa, relativa ao reconhecimento da condição de singularidade. Ainda que não seja uma conquista concluída, já que, em cada país, é um problema atravessado por diferentes fatores, tais como desigualdades sociais, localidade, cor da pele etc, verifica-se que, lentamente, medidas sociais voltadas para a diminuição das desigualdades de gênero se aplicam em diversos países, considerados democráticos.

$\mathrm{Na}$ América do Sul, o Uruguai se destaca como o país que primeiro avançou no quesito "igualdade de gênero", ao menos no que se refere aos seus aspectos legislativos. Foi o primeiro país a admitir o divórcio pela vontade da mulher (em 1913) e o voto feminino (em 1927) e a estabelecer a igualdade de direitos entre homens e mulheres (em 1946), incluindo o direito ao exercício conjunto da autoridade parental. Trata-se de um país que, tendo se declarado laico em 1917, tem conseguido avançar significativamente em relação à igualdade de gênero, seguindo um ritmo muito diferente do Brasil (Portal Montevideo, 2018). No Brasil, direitos como esses foram adquiridos somente depois, como se discutirá mais à frente: o direito ao voto, em 1932; o divórcio, em 1977; e a igualdade de direito entre homens e mulheres, em 1988.

Comparando o contexto uruguaio com o brasileiro, no que diz respeito à instituição da guarda compartilhada, o panorama, não muito diferente do que foi acima descrito, aponta certa vantagem no andamento dos fatos para o Uruguai. Enquanto lá o exercício da guarda compartilhada dos filhos foi autorizado em 1946, no Brasil, até o final dos anos de 1990, não se fazia menção a ela nos textos das leis. Somente no ano de 2002, com o novo Código Civil, ela passou a ser parte da legislação e só se tornou uma prática em princípio frequente porque em 2014 torna-se legalmente obrigatória (Grisard Filho, 2014).

Assim, este estudo apresenta alguns aspectos históricos e jurídicos do processo de instituição da guarda compartilhada no Brasil e no Uruguai, fruto de um estudo teórico-documental e discute a relação entre sua instituição e a igualdade parental. Tendo em conta os processos sociais envolvidos na determinação da igualdade entre homens e mulheres, reflete-se, também, sobre os limites que a regulamentação desse modelo de guarda, inspirada em princípios igualitários e constitucionais, encontra na condução à igualdade parental. 


\section{MÉTODO}

Como foi mencionado inicialmente, este artigo consiste em um estudo teórico-documental realizado como parte de uma pesquisa qualitativa mais ampla, ainda em andamento, cujo objetivo é investigar as relações parentais estabelecidas por pais e mães que compartilham a guarda dos filhos, a partir de dados coletados no Brasil e no Uruguai. A pesquisa foi submetida à aprovação da Plataforma Brasil e sua realização foi autorizada pelo Comitê de Ética da Universidade uruguaia à qual estava vinculada. Todos os procedimentos éticos foram seguidos na produção deste trabalho, conforme as diretrizes da Resolução CNS 510/2016.

A etapa da coleta de dados foi dividida em dois momentos: um realizado no Rio de Janeiro (Brasil) e outro, em Montevidéu (Uruguai). Além de entrevistas com pais e mães, brasileiros e uruguaios, que compartilham a guarda dos filhos com pessoas do sexo oposto e pertencentes aos extratos sociais médios, foi desenvolvido um estudo dirigido sobre os aspectos jurídicos envolvidos na instituição legal da guarda compartilhada em cada país. Para o presente artigo, apenas os resultados obtidos por meio do estudo dirigido foram apreciados.

A discussão aqui apresentada consiste na organização de uma revisão narrativa da literatura (Rother, 2007), a partir de pesquisa documental e de leituras de teóricos do tema, feitas pelas autoras. A análise, dividida em dois tópicos, volta-se para a reflexão dos seguintes temas: os fatores históricos e jurídicos envolvidos na instituição da guarda compartilhada no Brasil e no Uruguai e que afetam o exercício das funções parentais; as possíveis repercussões que a regulamentação da guarda compartilhada podem ter no processo de diminuição das assimetrias de gênero, podendo conduzir à igualdade parental.

Foram analisados textos jurídicos considerados fundamentais para o embasamento de uma recomendação jurídica da guarda compartilhada. Com relação à legislação do Uruguai, são eles: Código Civil de la República Oriental del Uruguay, de 1946; Ley de Derecho Civil de las Mujeres n.10.783, de 1946; Constitución de la República Oriental del Uruguay, de 1967; e Código de la Niñez y Adolescencia de Uruguay (Lei 17.823, de 2004). Já com relação à legislação do Brasil, esses textos foram: Código Civil de 1916 (Lei 3.071, de 1916); Estatuto da Mulher Casada (Decreto-Lei n. 9.701, de 1946); Lei do Divórcio (Lei 6.515, de 1977); Constituição da República Federativa do Brasil, de 1988; Estatuto da Criança e da Adolescência (Lei 8.069, de 1990); Código Civil de 2002 (Lei $10.406,2002$ ) e as leis que instituem a guarda compartilhada no país (Lei 11.698 , de 2008, e Lei 13.058, de 2014). 


\section{RESULTADOS E DISCUSSÃO}

O direito ao exercício da guarda compartilhada no Uruguai e no Brasil: dois panoramas

Embora tradicionalmente as funções parentais caibam muito mais às mulheres do que aos homens, o poder de decisão sobre o destino da prole cabia aos homens. O primeiro passo na instituição da igualdade legal de gênero no reconhecimento do exercício das funções parentais foi, sem dúvida, a possibilidade juridicamente apresentada de se estender às mulheres o exercício do poder familiar, atribuindo a elas os mesmos poderes que tinham os homens, enquanto chefes de família. Isso ocorreu no Uruguai, anteriormente que no Brasil.

Como já foi mencionado, no Uruguai, as mulheres alcançaram direitos importantes muito antes daquelas de outros países do mundo. Foram as primeiras da América do Sul a terem o direito de pedir o fim de seus casamentos, graças a uma lei aprovada em 1913 que regulamentava o divórcio unilateral sem expressão de causa, e obtiveram o direito ao voto em 1932. Em 1946, foi aprovada a Lei 10.783, conhecida como a Ley de Derecho Civil de las Mujeres, que determinou, em seu artigo primeiro, a igualdade de direitos entre homens e mulheres no Uruguai (Artículo 10.- La mujer y el hombre tienen igual capacidad civil) e, assim, termina por estender a elas o direito ao exercício da Patria Potestad. (Artículo 11 - La patria potestad será ejercida en común por los cónyuges, sin perjuicio de las resoluciones judiciales que priven, suspendan o limiten su ejercicio o lo confieran a alguno de ellos o a otra persona, y de los convenios previstos por el artículo 172 del Código Civil), alterando o sentido do conceito de Patria Potestad até então apresentado no Código Civil do Uruguai.

Patria Potestad é um conceito jurídico do Direito de Família. Trata-se de um conjunto de direitos e obrigações, de poderes e deveres vinculados tanto às relações pessoais como patrimoniais dos filhos, seja no âmbito interno (relações entre pais/mães e filhos) ou no externo (frente a terceiros). A patria potestad pode ser exercida tanto pelos pais e mães - biológicos ou adotivos, de mesmo sexo ou de sexos diferentes - quanto por outras pessoas que possam e precisem eventualmente assumir esta responsabilidade. No primeiro Código Civil do Uruguai, de 1869, determinava-se que a patria potestad fosse desempenhada quase sempre exclusivamente pelo pai, na sua condição de chefe de família. A mãe só a exercia em condição de suplência, isto é, na ausência do pai ou por seu falecimento. Mesmo em casos de divórcio (desde os primeiros anos do século XX, o divórcio já era aceito no Uruguai), estando vivos ambos os cônjuges, até 1946 eram homens que exerciam a patria potestad - diferentemente do que ocorre atualmente, quando ela é considerada uma função que os pais e as mães devem exercer em conjunto, em favor do desenvolvimento de sua prole (Howard, 1999). 
A partir de 1946, o conceito de Patria Potestad ficou definido na legislação do Uruguai, artigo 252 do código civil, da seguinte forma: "La patria potestad es el conjunto de derechos y deberes que la ley atribuye a los padres en la persona y en los bienes de sus hijos menores de edad". Ao estabelecer que "La patria potestad será ejercida en común por los padres, sin perjuicio de las resoluciones judiciales que priven, suspendan o limiten su ejercicio o lo confieran a uno de ellos y de los convenios previstos en el artículo 172", garantiu-se que, a partir daquele ano, ambos, pai e mãe, tivessem o direito de exercer conjuntamente a guarda jurídica de seus filhos, estando ou não casados legalmente.

A mudança na definição da Patria Potestad no Uruguai, trazendo para as mulheres o direito de exercerem, em pé de igualdade com os homens, a responsabilidade jurídica pelos filhos, significou um passo importante em direção à igualdade de gênero. Entretanto, o fato de não haver, no Código Civil de la República Oriental del Uruguay, uma norma específica sobre a Guarda Compartilhada, como há, atualmente, no Brasil, acabou impedindo que tais avanços se desdobrassem em um padrão igualitário de relação parental.

Assim, no Uruguai, o exercício conjunto da guarda jurídica por ambos os pais está respaldado, juridicamente, desde 1946, pelo conceito de Patria Potestad apresentado no artigo 252 do Código Civil daquele ano; pela igualdade de direito entre homens e mulheres, assegurada pela Ley de Derecho Civil de las Mujeres n.10.783, de 1946, e pelos deveres que competem aos pais com relação a seus filhos, conforme os artigos 40, 41 e 42 da Constitución de la República Oriental del Uruguay, de 1967. Não há determinações legais sobre como os pais devem definir a posse dos filhos, isto é, sobre como eles devem dividir as tarefas parentais no dia a dia. Geralmente, isso se define por meio de um acordo feito entre os possuidores da Patria Potestad. Segundo o estabelecido no Código Civil do Uruguai, "la intromisión de los órganos judiciales en el ejercicio de la patria potestad solo admite justificación cuando exista una decisión manifiestamente absurda o prejudicial para los intereses de los menores" (Howard, 1999, p.284). Por isso, o juiz somente estabelece parâmetros mais objetivos sobre a convivência dos pais com os filhos quando não há acordo satisfatório entre eles (Howard, 1999), mostrando que ao Estado só cabe, nesses casos, intervir eventualmente, de forma bem pontual.

Cabe lembrar: não se edita sentença de divórcio sem que estejam definidos guarda jurídica, posse, regime de visita e pensão alimentícia; poderão ter a posse dos filhos ambos os cônjuges ou um terceiro, ou repartida entre eles, mantendo a Patria Potestad com os pais; as questões relativas à "posse dos filhos" ("tenencia de los hijos" ou "guarda de hecho") são definidas sempre considerando o melhor para a criança, de acordo com o que dispõem os artigos 34 a 37 do Código de la Niñez y Adolescencia (Lei 17.823, de 2004), cabendo aí interferências subjetivas do juiz responsável por cada caso apenas quando necessário (Howard, 1999). Portanto, estando definida Guarda Jurídica 
Compartilhada e não havendo acordo entre pais e mães sobre quem ficará com a "posse dos filhos", ou sobre como eles compartilharão as tarefas parentais, o juiz, tomando como base o Código de la Niñez y de la Adolescencia, é quem determina o que the parece melhor para o desenvolvimento dos filhos.

A restrita interferência jurídica sobre o processo de determinação da divisão das tarefas parentais, se por um lado reforça a autonomia de homens e mulheres para decidirem sobre suas próprias vidas, por outro lado vem alimentando o crescimento de associações de pais, tais como a "SOS Papá" e a "Todo por Nuestros Hijos", criadas para orientá-los e apoiá-los em suas negociações com as mães de seus filhos em vários países do mundo (SOS Papá, 2018; Todo por Nuestros Hijos, 2014). Em 2017, um legislado uruguaio propôs alterar o texto do referido artigo 34, explicitando para os juízes que o tempo de contato de pais e mães com os filhos deve ser dividido de modo que se garanta um contato equivalente entre eles (El País, 2017 agosto 28), considerando justamente a existência de empecilhos culturalmente constituídos ao exercício da paternidade fora da relação conjugal. No entanto, o projeto segue em trâmite no congresso, mas encontra barreiras para ser aprovado frente ao debate aberto sobre os limites de atuação do poder jurídico na vida pessoal. Embora se reconheça amplamente a tendência a se confiar o cuidado diário dos filhos às mães, especialistas consideram que é preferível que pais e mães cheguem a um acordo, considerando as necessidades das crianças, e não acham apropriado que alguns pontos mais específicos sobre a convivência familiar, tais como as horas que cada pai fica com seus filhos, sejam impostos ou definidos a priori em alguma lei (Canal 180, 2018 octubre $1^{\circ}$ ).

Vê-se, portanto, que, embora a guarda jurídica compartilhada exista, desde 1946, no Uruguai, quando a coabitação dos pais já não existe, ainda prevalece a ideia de que são as mães que devem permanecer com os filhos, mesmo cabendo a ambos a divisão das responsabilidades legais. Deste modo, observa-se que a alteração legal, que institui a igual responsabilidade da mãe e do pai na criação dos filhos, não chega a representar efetivamente um avanço em termos de igualdade nas relações parentais no exercício cotidiano, ainda que tenha apontado o grande avanço de implicar ambos nas decisões importantes sobre a vida de crianças e de adolescentes.

Vejamos como isso vem ocorrendo no Brasil. Aqui, a instituição da guarda compartilhada ocorreu em um ritmo bastante diferente. Entretanto, apesar desta desvantagem temporal, avanços consideráveis foram alcançados, ao menos no que diz respeito à regulamentação de uma forma mais igualitária de relações parentais, uma vez que a legislação brasileira, diferentemente da uruguaia, já prevê a necessidade de haver um equilíbrio no tempo de permanência dos pais com os filhos. Se a inserção desta diretriz na lei não induz uma transformação imediata nas relações cotidianas, ao menos indica caminhos mais equânimes na 
divisão das tarefas e das responsabilidades parentais e vai ao encontro do desejo de muitos pais de estarem mais próximos e presentes na vida de seus filhos.

O princípio da igualdade entre cônjuges e companheiros na chefia familiar afirmou-se, no Brasil, mais de 50 anos depois do Uruguai. A Constituição Federal, de 1988, declara igualdade entre homens e mulheres e, em seu artigo 226, afirma que os direitos e deveres relativos à sociedade conjugal são exercidos igualmente pelo homem e pela mulher e aborda a responsabilidade conjunta sobre o planejamento familiar. Na mesma linha da $\mathrm{CF}$, a chamada depatriarcalização do Direito de Família ocorreu definitivamente em 2002, com a substituição dos termos pater familias ou pátrio poder no Código Civil Brasileiro, que historicamente conferia à figura do "chefe de família" poder sobre as mulheres e os filhos. Em seu lugar, passou a ser usado o termo poder familiar, que pressupõe a igualdade de direitos de homens e mulheres no exercício da chefia familiar, de forma cooperativa e não hierárquica, trazendo a possibilidade de haver uma guarda jurídica compartilhada (Grisard Filho, 2014).

Anteriormente ao Código Civil de 2002 (Lei 10.406, de 2002), especificamente a atribuição da guarda dos filhos era um assunto tratado pelos artigos 325 a 328 do Código Civil de 1916 (Lei 3.071, de 1916), que foram posteriormente modificados pelo Estatuto da Mulher Casada (Decreto de Lei 9.701, de 1946) e pela Lei do Divórcio (Lei 6.515, de 1977). De forma breve, observa-se que a separação do casal, geralmente, seguia a atribuição de guarda unilateral dos filhos, com base em critérios como a culpa ou inocência do cônjuge na causação do divórcio (a pessoa considerada inocente teria preferência na guarda). Caso não houvesse inocentes, a guarda era quase sempre atribuída à mãe, considerando-a, via de regra, possuidora natural dos atributos demandados no cuidado dos filhos. A parte que não tivesse a posse dos filhos, geralmente o pai, permanecia possuidor do direito de visitar os filhos e fiscalizar a atividade do genitor guardião.

A partir do final da década de 1980 , iniciou-se um processo de mudança importante no que tange à instituição da igualdade de gênero nas relações parentais. Primeiramente, a nova Constituição Federal estabeleceu a igualdade entre homens e mulheres na sociedade conjugal, como mencionado; o Brasil aderiu à Convenção sobre os Direitos da Criança adotado pela Assembleia Geral das Nações Unidas em 1989 e instituiu o Estatuto da Criança e do Adolescente em 1990 (Lei 8.069, de 1990). Assim, como afirma Grisard Filho (2014), rompeu-se "com o sistema precedente, que vinculava a guarda dos filhos à verificação da culpa de um dos cônjuges pela separação, determinando que, na falta de acordo entre os pais, a guarda será atribuída a quem revelar melhores condições para exercê-la" (p. 157). O Código Civil de 2002, construído a partir dessas novas diretrizes, reconheceu o direito dos filhos ao convívio com pais e mães, sinalizando a possibilidade de que estes exercessem conjuntamente a guarda dos filhos. 
Entretanto, com o novo Código Civil não ficava clara a necessidade de que a guarda dos filhos fosse compartilhada, mas apenas indicava esta possibilidade. Por isso, como no Uruguai, ganhou impulso no Brasil o movimento de pais em favor do aprofundamento deste debate. Formaram-se associações que tinham como objetivo reunir pais que estivessem vivenciando algum tipo de impedimento para conviver com seus filhos, geralmente causado por suas excompanheiras, progenitoras dos seus filhos. Movimentos de pais como, por exemplo, o "Pai legal", o "SOS Papai", "Associação de Pais e Mães Separados" (APASE) e a "Associação Pais Para Sempre" são protagonistas na luta pela ampla aplicação da guarda, considerando esta uma forma de proteger os direitos dos pais e se defender do que veio se configurando, do ponto de vista jurídico, como alienação parental - lei 12.318, de 2010. Ressalta-se, ainda, que justamente esses pais que se engajaram nessa questão foram os responsáveis pelo encaminhamento de um pré-projeto de lei que trata da guarda compartilhada e que origina a primeira lei da guarda compartilhada, em 2008 (Franco, Magalhães, \& Féres-Carneiro, 2018; Pailegal, 2019; SOS Papai, 2018).

Como consequência, a lei brasileira $11.698 / 2008$ alterou os artigos 1.583 e 1.584 da lei 10.046 do Código Civil de 2002, para instituir e disciplinar a guarda compartilhada, contudo sem fazer desaparecer a possibilidade de guarda unilateral. Ela determina que "a guarda será unilateral ou compartilhada" (artigo 1.583) e que "quando não houver acordo entre a mãe e o pai quanto à guarda do filho será aplicada, sempre que possível, a guarda compartilhada" (artigo 1.584, parágrafo $2^{\circ}$ ). Em 2014, foi aprovada a lei $13.058 / 2014$, que dispõe sobre o significado da expressão "guarda compartilhada" e sobre sua aplicação, tornando-a obrigatória para todos os casais. "Quando não houver acordo entre a mãe e o pai quanto à guarda do filho, encontrando-se ambos os genitores aptos a exercer o poder familiar, será aplicada a guarda compartilhada, salvo se um dos genitores declarar ao magistrado que não deseja a guarda do menor" (artigo 1.584, parágrafo $2^{\circ}$ ). Esta lei prevê, ainda, a divisão equilibrada do tempo atribuído aos pais, como se pode ver: "Na guarda compartilhada, o tempo de convívio com os filhos deve ser dividido de forma equilibrada com a mãe e com o pai, sempre tendo em vista as condições fáticas e os interesses dos filhos" (artigo 1.583, parágrafo $2^{\circ}$ ).

Verifica-se, assim, que, diferentemente do Uruguai, no Brasil há uma lei que torna a guarda compartilhada um regime obrigatório para pais que não vivem sob o mesmo teto, exceto nos casos em que haja impedimento de uma das partes, previsto em lei, ou que um deles não o deseje. Por isso, pais e mães brasileiros têm se deparado, desde 2014, com a necessidade de compartilhar não somente a responsabilidade jurídica em relação aos filhos, mas também as tarefas parentais, cotidianamente, adaptando-se ao que está na lei. 


\section{A luta pela igualdade parental: resultados fáticos ou concretos?}

Como se pode observar, em ambos os países, Brasil e Uruguai, a instituição da guarda compartilhada foi inspirada tanto na valorização da afetividade quanto em princípios igualitários e pode ser compreendida sob diferentes ângulos. O direito ao exercício da guarda jurídica compartilhada pode ser visto tanto como ratificação da propriedade feminina da mulher de exercício de cuidado, quanto como uma conquista das mulheres, no sentido do reconhecimento de um direito anteriormente restrito aos homens, até então incompatível com as atribuições do cotidiano. Se a ideia naturalizada do amor materno gerava uma expectativa em relação ao cuidado por parte das mulheres e manteve, por muito tempo, a certeza da necessidade de mãe como imprescindível, agora este aspecto da vida se transformava em direito adquirido.

Do ponto de vista dos homens, a instituição da guarda compartilhada pode assumir outro significado. Não havendo uma expectativa social em torno do seu papel afetivo com relação aos seus filhos, o direito ao exercício conjunto da guarda de fato é o resultado de mobilizações protagonizadas por eles, pautadas na reivindicação de um novo lugar para os homens na família que não se restringisse ao de provedor (Leite, 2013 junho). Formaram-se, assim, pelos próprios pais, organizações não governamentais com o objetivo de oferecer apoio e orientação a homens que estivessem enfrentando dificuldades para dar continuidade ao convívio com seus filhos após a separação do casal e, principalmente, nos casos em que a mãe dificulta ou impede o contato com o pai. A declarada expressão do desejo de muitos pais de participar mais ativamente da criação dos seus filhos sensibilizou a sociedade e as autoridades atuantes a respeito da necessidade de fazer avançar a discussão da igualdade parental.

É interessante notar que esses movimentos protagonizados por pais ocorreram mesmo no Uruguai, onde a possibilidade de compartilhamento da guarda jurídica foi tão precocemente estabelecida. Ainda que, lá, o direito ao exercício conjunto da pátria potestad já fosse assegurado desde 1946 e, portanto, já se apontassem avanços no que se refere à instituição da igualdade de gênero na sociedade de uma forma geral, isso não se traduziu em padrões igualitários de relações parentais. Não havendo uma lei que especificasse como deveria ser o exercício das relações parentais, ocorreu que lá, uma vez estabelecida a guarda jurídica compartilhada, o mais comum era que os juízes procedessem como se as mães tivessem mais poder do que os pais frente aos filhos, à força dos costumes e de posturas tradicionalistas, influenciados pelo mito do amor materno. Desconhecemos o que motivou os legisladores na primeira metade do século passado a garantir a igualdade de direitos, mas talvez, efetivamente, os desdobramentos sociais disso tenham sido mais tardios.

Deste modo, no Uruguai, como também no Brasil, apenas recentemente uma relação parental mais igualitária se tornou declaradamente desejada e até 
possível. Mas se a possibilidade do exercício conjunto da guarda jurídica por homens e mulheres, fruto do reconhecimento de direitos, não gerou necessariamente uma relação de igualdade parental em termos práticos, como demonstram alguns estudos (Hirata, 2015; Sousa \& Guedes, 2016), talvez ela tenha contribuído para a formação de um campo de tensão e disputa em torno do exercício da autoridade e da afetividade em relação aos filhos.

Apesar dos diferentes sentidos que se pode atribuir à guarda compartilhada, em razão das distintas perspectivas que as relações sociais constroem para pais e mães, é certo que a luta pela igualdade parental envolve causas associadas a reivindicações de vários segmentos. Trata-se de uma luta pelos direitos de mulheres, de homens, de crianças, pelos direitos humanos e pela igualdade de gênero, como assinala Montaño (2016). O autor defende que a guarda compartilhada, sim, é um passo importante na aplicação do princípio da igualdade entre homens e mulheres. Convém ressaltar que o papel precípuo da lei é garantir os direitos e este passo já foi dado. Entretanto, pode-se questionar até que ponto esta igualdade alcançada no plano fático tem realmente alcance para transformar, no plano mais concreto da vida das pessoas, as relações entre pais e mães.

A esse respeito, Montaño (2016) afirma que a guarda compartilhada pode realmente favorecer a igualdade parental, desde que os pais realmente se empenhem em exercer na prática uma divisão equilibrada de seus tempos e de suas responsabilidades, junto aos filhos. Segundo ele, com essa divisão todos se beneficiam: os filhos, as mães, os pais e a sociedade. Favorece os filhos, pois permanecem próximos a ambos, convivendo com eles em uma divisão de tempo equilibrada, o que pode favorecer uma referencialidade de ambos por parte da criança. Os pais e as mães, pois a guarda compartilhada funciona como uma medida pedagógica, forçando-os a resolverem seus conflitos para, então, serem capazes de priorizar os interesses dos filhos. Além disso, ela propicia a cada um uma maior possibilidade de refazer sua vida amorosa e/ou sexual, caso seja de seu interesse, o que se torna mais difícil para alguém que assume integralmente a responsabilidade pelos filhos. $E$ favorece a sociedade, provocando-a na desconstrução de tradicionais referências, contrárias à noção de equidade de gênero, como, por exemplo, o ideal da parentalidade calcado no modelo da "mãe-cuidadora e do lar" e do "pai-provedor e trabalhador".

Montaño (2016) critica arranjos de guarda compartilhada que não permitam aos pais a divisão igualitária das tarefas parentais, como aquele da "guarda compartilhada com guarda (física) unilateral e/ou regime de visita quinzenal". De acordo com ele, esse tipo de guarda compartilhada não promove a igualdade parental e não é suficiente para desconstruir certas crenças que fundamentam a desigualdade das relações parentais. É preciso, então, que pais e mães de fato possam se incumbir mais efetivamente da criação dos filhos. 
Deste modo, pode-se considerar necessária a indicação, em termos de leis ou, quando não há uma lei específica sobre isso, como é o caso do Uruguai, de alguma forma de aconselhamento feito via justiça, de normas para direcionar as condutas parentais, visando a equilibrar a atuação de pais e mães junto aos filhos. O estabelecimento de alguns parâmetros que garantam a participação mais equilibrada de pais e mães nas tarefas parentais corresponde justamente ao que foi reivindicado por pais que se engajaram no movimento da guarda compartilhada e acabou influenciando o modo como a lei 13.058/2014 determina que a guarda compartilhada seja aplicada no Brasil.

Contudo, é interessante notar, como assinalam Vogel e Verjus (2016), que o movimento de pais pela guarda compartilhada, com foco na posse dos filhos, tem sua reivindicação de igualdade nas relações parentais circunscrita apenas ao contexto pós-separação. Além disso, atenta-se para o fato de a igualdade parental ser reivindicada por eles em termos de "direito dos pais" e não de "dever dos pais" em relação a seus filhos e à vida familiar, admitindo a guarda compartilhada com alternância de residência, por exemplo, que é uma das formas frequentemente adotadas para se equiparar as responsabilidades paternas às maternas, como uma possibilidade para eles, caso assim desejem.

É claro que um modelo mais igualitário de relação parental poderia ser projetado também para pais e mães que vivem juntos. Hoje, é uma realidade frequente que mulheres se dediquem à carreira profissional, almejando realização, sucesso e ganhos financeiros, e que homens experimentem mais atividades antes reservadas às mulheres (Borges, 2013; Castro, 2009; Freitas \& Silva, 2009; Hirata \& Kergoat, 2007). Entretanto, ainda é uma realidade frequente que mulheres casadas e com filhos, quando têm uma profissão ou um trabalho formal, acabem realizando uma dupla jornada, pois quando retornam para casa continuam sendo responsáveis pelas atividades domésticas, o que inclui não somente atividades ligadas à manutenção da casa, mas também ao cuidado dos filhos. Ao mesmo tempo, o envolvimento dos homens com questões próprias da vida doméstica, inclusive em relação à criação dos filhos, principalmente quando têm uma vida conjugal, permanece apenas como uma possibilidade (Andrade, 2016; Bruschini, 2007; Instituto de Pesquisa Econômica Aplicada [IPEA], 2018; Soares \& Sabola, 2007).

Enquanto as responsabilidades maternas seguirem sendo inquestionáveis e naturalizadas e a participação paterna na criação dos filhos for reivindicada em termos de direitos dos homens, convém indagar-se sobre que tipo de igualdade parental se está edificando. Como assinala Hirata (2015), a luta pela igualdade não é uma luta específica de certos grupos, de modo que romper com as desigualdades de gênero depende de amplas transformações desenroladas em diferentes espaços da divisão de trabalho. Portanto, conclui-se, neste estudo, que o processo de instituição da igualdade parental, embora se beneficie da existência de leis como a que regulamenta a guarda compartilhada e de medidas 
voltadas para o estabelecimento de parâmetros que normatize sua aplicação cotidiana, depende de outros ajustes, mais específicos, voltados e operados na prática cotidiana de homens e mulheres com seus filhos, ao longo de suas trajetórias. Assim, a igualdade nas relações parentais só se estabelecerá por meio de uma mudança cultural mais profunda, que pode ser influenciada, embora não determinada, pelas leis.

\section{CONSIDERAÇÕES FINAIS}

Contrastando-se os processos de instituição da guarda compartilhada no Brasil e no Uruguai, revelam-se as tensões em torno do processo de desconstrução das diferenças de gênero que sustentam as desigualdades de gênero nas relações parentais. A análise dos casos do Brasil e do Uruguai permitiu observar que a demanda pela igualdade de gênero, produzida a seu tempo em cada país, assume significados distintos. De um lado, estavam as mulheres, lutando pela igualdade, em um sentido mais amplo, e conquistando direitos até então restritos aos homens. De outro lado, encontram-se os homens, mobilizados em torno da conquista de reconhecimento social sobre sua importância afetiva em relação aos seus filhos. Assim, a instituição da guarda compartilhada se configura como um campo de disputas e tensões entre homens e mulheres que contribui para o fortalecimento da igualdade de gênero.

Compreende-se o estabelecimento deste modelo de custódia como o resultado de uma dupla demanda de ampliação de direitos e de reconhecimento social, protagonizada, primeiramente, por mulheres e, posteriormente, por homens. Obviamente, não se trata aqui de desconsiderar as diferentes dimensões que tiveram o movimento de mulheres pela garantia de igualdade de direitos e as reivindicações de homens/pais pelo direito de exercer a paternidade de forma mais presente no cotidiano de seus filhos. Consideramos que 0 movimento pela guarda compartilhada resultou de ambas as mobilizações, tanto das mulheres quanto dos homens, mais coletivas ou mais coletivizadas e em diferentes momentos históricos e políticos em cada um dos países, atravessadas pelas questões vividas pela sociedade mais ampla.

É fato que a guarda compartilhada pode ser um dispositivo potente rumo à democratização das relações parentais. Ela é, sim, o resultado de mudanças operadas com o propósito de instituir medidas mais igualitárias, seguindo a legislação maior de cada um dos dois países, produzidas em momentos distintos. Mas, é preciso afirmar que seria ingenuidade concluir que o regime da guarda compartilhada seja suficiente para produzir uma relação igualitária entre pais e mães. Há de se reconhecer que a regulamentação desse modelo de guarda, inspirada em princípios igualitários e constitucionais, encontra limites para conduzir à igualdade parental, já que é no cotidiano, nas lutas e nas produções 
de novos sentidos, que filhos e filhas conviverão mais com seus pais e suas mães, sendo este um problema comum às famílias contemporâneas.

Tanto no Uruguai quanto no Brasil, tem sido um desafio para homens e mulheres desconstruir as tradicionais referências sobre paternidade e maternidade absorvidas das outras gerações, para apostar em novos modelos igualitários de parentalidade. Esta situação não se apresenta apenas às famílias em que há guarda compartilhada. Mudanças nos padrões relacionais entre pais, mães e filhos, ligados à individualização e à democratização das relações, vêm ocorrendo também entre aqueles que vivem como casal e precisam responder às necessidades que se configuram e se apresentam aos indivíduos na contemporaneidade.

Nesse sentido, a reivindicação de um modelo igualitário de custódia dos filhos, que resulta de mudanças lentamente estabelecidas, voltadas para a instituição da igualdade de gênero e da parentalidade, como foi discutido, reforça um movimento que já existe nas famílias contemporânea, referente à ampliação dos domínios de atuação de homens e mulheres na sociedade. Instituindo-se a guarda compartilhada, são fixados novos parâmetros que definem os papéis de pai e de mãe na família, tensionando em favor da criação de um novo padrão de parentalidade, ainda desconhecido pelos seus protagonistas. Com isso, compreende-se que a guarda compartilhada seja vivenciada como uma provocação para homens e mulheres que, envolvidos no espírito de contestação e da ousadia, se propuseram novos direitos e agora estão tendo que encontrar novas formas de ser pais e mães, incorporando princípios igualitários em suas práticas parentais, para além da conjugalidade.

São ainda escassos os estudos que tratam dessa nova realidade familiar. Nesse sentido, mais investigações precisam ser realizadas, considerando-se o cotidiano e as experiências de pais e mães, bem como de filhos, que vivenciam a guarda compartilhada. Deve-se avaliar, também, o impacto desta forma de parentalidade na rede familiar de uma forma mais ampla, verificando, por exemplo, se, nesse contexto, novas funções são atribuídas a parentes como avós e tias. O estabelecimento de novos contratos com a rede de parentela pode estar relacionado com mudanças e permanências de padrões de gênero na família.

Configura-se, assim, um tema de grande relevância para a compreensão das relações familiares na contemporaneidade e um campo de estudo bastante promissor. É preciso conhecer melhor as relações que estão se constituindo nesse contexto e compreender o padrão de igualdade parental que se expressa na guarda compartilhada.

\section{DECLARAÇÃO DE CONFLITOS DE INTERESSE}

Não há conflito de interesse. 


\section{REFERÊNCIAS}

Andrade, T. (2016). Mulheres no mercado de trabalho: onde nasce a desigualdade? Publicações da consultoria legislativa. Recuperado de https://www2.camara.leg.br/atividade-legislativa/estudos-e-notas-

tecnicas/publicacoes-da-consultoria-legislativa/areas-da-

conle/tema7/2016 12416 mulheres-no-mercado-de-trabalho taniaandrade

Ariès, P. (2006). História social da criança e da família (2a ed.). Rio de Janeiro: LTC.

Badinter, E. (1998). Um amor conquistado: o mito do amor materno (9a ed.). Rio de Janeiro: Nova Fronteira.

Beauvoir, S. (1980). O segundo sexo, 2: a experiência vivida (4a ed.). Rio de Janeiro: Nova Fronteira.

Borges, C. C. (2013). Mudanças nas trajetórias de vida e identidades de mulheres na contemporaneidade. Psicologia em Estudo, 18(1), 71-81. http://dx.doi.org/10.1590/S1413-73722013000100008.

Bruschini, M.C.A. (2007) Trabalho e gênero no Brasil nos últimos dez anos. Cadernos de Pesquisa, 37(132), 537-572, set./dez. http://dx.doi.org/10.1590/S0100-15742007000300003.

Canal 180. (2018, octubre $\left.1^{\circ}\right)$. Tenencia compartida: no es dividir el tiempo sino tener el mayor contacto posible. Recuperado de https://www.180.com.uy/articulo/76305 tenencia-compartida-no-esdividir-el-tiempo-sino-tener-el-mayor-contacto-posible

Cardoso, V. M. (2006). O Abuso do Direito na Perspectiva Civil-Constitucional. In M. C. B., Moraes (Coord.). Princípios do Direito Civil Contemporâneo. Rio de Janeiro: Renovar. Recuperado de https://bdjur.stj.jus.br/jspui/bitstream/2011/9122/Princ\%C3\%ADpios do Direito \%20Civil\%20Contempor\%C3\%A2neo.pdf

Castro, M.G. (2009). Família, população, sexo e poder. São Paulo: Paulinas.

Código Civil de la República Oriental de Uruguay de 1946. Recuperado de http://www.wipo.int/edocs/lexdocs/laws/es/uy/uy029es.pdf

Constituição da República Federativa do Brasil de 1988. Recuperado de http://www.planalto.gov.br/ccivil 03/Constituicao/Constituicao.htm

Constitución de la República Oriental del Uruguay de 1967. Recuperado de http://pdba.georgetown.edu/Parties/Uruguay/Leyes/constitucion.pdf

Côté, D. (2016). Guarda compartilhada e simetria nos papéis de gênero: novos desafios para a igualdade de gênero. Revista Observatório, 2(3), 182-198. https://doi.org/10.20873/uft.2447-4266.2016v2n3p182 
Daltro Filho, H. F. (2014). Guarda Compartilhada: realidade contemporânea para proteção dos interesses dos filhos. Revista Jurídica Unic/Emam, 1(2), jan/jun. Recuperado de http://revistaemam.kinghost.net/revista/index.php/unicemam/article/view/ $\underline{147}$

Decreto-Lei n. 9.701, de 3 de setembro de 1946. Dispõe sobre a guarda dos filhos menores, no desquite judicial. Recuperado de http://www.planalto.gov.br/ccivil 03/decreto-lei/1937-1946/Del9701.htm

De Singly, F. (2005). Le soi, le couple et la famille. Paris, França: Armand Colin.

De Singly, F. (2007). L'individualisme est un humanisme. Paris, França: Éditions de I'Aube.

Dumont, L. (1983). Essais sur I'individualisme: une perspective anthropologique sur I'idéologie moderne. Paris, França: Éditions du Seuil.

El País. (2017, agosto 28). Propuesta para velar por mayor equidad en la tenencia de niños. Recuperado de https://www.elpais.com.uy/informacion/propuesta-velar-mayor-equidadtenencia-ninos.html

Franco, D. A., Magalhães, A. S., \& Féres-Carneiro, T. (2018). Luta pela guarda compartilhada: narrativa dos pais. Interação em Psicologia, 22(2), 155-165. http://dx.doi.org/10.5380/psi.v22i2.55760

Freitas, W. M. F., \& Silva, A. T. M. C. (2009). Paternidade: responsabilidade social do homem no papel de provedor. Revista de Saúde Pública, 43(1), 85-90. Recuperado de http://www.scielo.br/pdf/rsp/v43n1/6868.pdf

Grisard Filho, W. (2014). Guarda compartilhada: um novo modelo de responsabilidade parental ( 7 a ed). São Paulo: Editora Revista dos Tribunais.

Hirata, H., \& Kergoat, D. (2007). Novas configurações da divisão sexual do trabalho. Cadernos de Pesquisa, 37(132), 595-609, set-dez. http://dx.doi.org/10.1590/S0100-15742007000300005.

Hirata, H. (2015). Mudanças e permanências nas desigualdades de gênero: divisão sexual do trabalho numa perspectiva comparada. Friedrich Ebert Stiftung Brasil, 7. Recuperado de https://library.fes.de/pdffiles/bueros/brasilien/12133.pdf

Howard, W. (1999). Patria Potestad: representación y administración legales. Revista Asociación de Escribanos del Uruguay, 85(7-12), 279-297. Recuperado de http://documentos.aeu.org.uy/080/085-7-279-297.pdf

Instituto de Pesquisa Econômica Aplicada. (2018). Mulheres dedicam muito mais tempo ao trabalho doméstico, mas a diferença cai. Recuperado de http://www.ipea.gov.br/portal/index.php?option=com content\&view=article \&id $=34450$ \&Itemid $=9$

Lash, C. (1991). Refúgio num mundo sem coração. A família: santuário ou instituição sitiada? Rio de Janeiro: Paz e Terra. 
Lei 3.071, de $1^{\circ}$ de janeiro de 1916. Código Civil dos Estados Unidos do Brasil. Recuperado de http://www.planalto.gov.br/ccivil 03/Leis/L3071.htm

Lei 10.783, de 18 de setembro de 1946. Ley de Derecho Civil de las Mujeres. Capacidad civil de la Mujer. Se equiparan sus derechos a los del hombre dandoselas disposiciones atingentes. Recuperado de https://legislativo.parlamento.gub.uy/temporales/leytemp3969200.htm

Lei 6.515, de 26 de dezembro de 1977. Regula os casos de dissolução da sociedade conjugal e do casamento, seus efeitos e respectivos processos, e dá outras providências. Recuperado de http://www.planalto.gov.br/ccivil 03/leis/l6515.htm

Lei 8.069, de 13 de julho de 1990. Dispões sobre o Estatuto da Criança e do Adolescente e dá outras providências. Recuperado de http://www.planalto.gov.br/ccivil 03/leis/L8069Compilado.htm

Lei 10.406, de 10 de janeiro de 2002. Institui o Código Civil. Recuperado de http://www.planalto.gov.br/ccivil 03/leis/2002/L10406.htm

Lei 17.823, de 14 de setembro de 2004. Código de la Niñez y Adolescencia. Recuperado de https://www.oas.org/dil/esp/Codigo Ninez Adolescencia Uruguay.pdf

Lei 11.698, de 13 de junho de 2008. Altera os artigos 1.583 e 1.584 da Lei n.10.406, de 10 de janeiro de 2002 - Código Civil, para instituir e disciplinar a guarda compartilhada. Recuperado de http://www.planalto.gov.br/ccivil 03/ ato2007-2010/2008/lei/l11698.htm

Lei 12.318, de 26 de agosto de 2010. Dispõe sobre a alienação parental e altera o art. 236 da Lei no 8.069, de 13 de julho de 1990. Recuperado de http://www.planalto.gov.br/ccivil 03/ ato2007-2010/2010/lei/l12318.htm

Lei n.13.058, de 22 de dezembro de 2014. Altera os arts. $1.583,1.584,1.585$ e 1.634 da Lei no 10.406, de 10 de janeiro de 2002 (Código Civil), para estabelecer o significado da expressão "guarda compartilhada" e dispor sobre sua aplicação. Recuperado de http://www.planalto.gov.br/CCIVIL 03/ Ato20112014/2014/Lei/L13058.htm

Leite, E. O. (2003). Famílias monoparentais: a situação jurídica de pais e mães solteiros, de pais e mães separados e dos filhos na ruptura da vida conjugal ( $2^{a}$ ed). São Paulo: Editora Revista dos Tribunais LTDA.

Leite, A. F. D. (2013, junho). Da construção do espaço familiar aos vínculos de afetividade entre os homens/pais e filhos e o compartilhamento da guarda. III Simpósio mineiro de assistentes sociais. Belo Horizonte, Belo Horizonte, MG, Brasil, 3. Recuperado de http://www.cressmg.org.br/arquivos/simposio/DA\%20CONSTRU\%C3\%87\%C3\%830\%20DO \%20ESPA \%C3\%870\%20FAMILIAR\%20\%20AOS\%20V\%C3\%8DNCULOS\%2 ODE\%20AFETIVIDADE\%20ENTRE $\% 2005 \% 20$ HOMENSPAIS\%20E\%20FILHO S\%20E\%200\%20COMPARTILHAMENT.pdf 
Montaño, C. (2016). Alienação parental e guarda compartilhada: um desafio ao Serviço Social na proteção dos mais indefesos: a criança alienada. Rio de Janeiro: Lumen Juris.

Nardi, H. C. (2008). O estatuto da diversidade sexual nas políticas de educação no Brasil e na França: a comparação como ferramenta de desnaturalização do cotidiano de pesquisa. Psicologia \& Sociedade, 20(spe), 12-23. http://dx.doi.org/10.1590/S0102-71822008000400004.

Pailegal. (2019). Pailegal, pai legal ou pai legal? Quem somos? Recuperado de http://www.pailegal.net/index.php/quem-somos

Ponciano, E. L. T., \& Féres-Carneiro, T. (2017). Conjugalidade, parentalidade e separação: repercussões no relacionamento pais e filhos (as). Psicologia em estudo, 22(2), 277-287. http://dx.doi.org/10.4025/psicolestud.v22i2.32808

Portal Montevideo. (2018). Uruguay, sexto en el mundo en derechos políticos y libertades civiles. Recuperado de https://www.montevideo.com.uy/Noticias/Uruguay-sexto-en-el-mundo-enderechos-politicos-y-libertades-civiles-uc672488

Prado, C. G. S., \& Barros, J. N. (2016). O abandono afetivo e a guarda compartilhada como garantia da convivência familiar. Revista Universitári@, 7, 278-287. Recuperado de http://www.salesianolins.br/universitaria/artigos/no15/artigo47.pdf

Prost, A., \& Vincent, G. (Orgs.). (1999). Histoire de la vie privée: de la première guerre mondiale à nos jours. Paris, França: Éditions du Seuil.

Resolução n. 510, de 07 de abril de 2016. Dispõe sobre as normas aplicáveis a pesquisas em ciências humanas e sociais. Recuperado de http://conselho.saude.gov.br/resolucoes/2016/Reso510.pdf

Rocha-Coutinho, M. L. (2000). Dos contos de fadas aos superheróis: mulheres e homens brasileiros reconfiguram identidades. Psicologia Clínica, 12(2), 6582. Recuperado de http://pesquisa.bvsalud.org/brasil/resource/pt/psi34372

Rother, E. T. (2007). Revisão sistemática vs revisão narrativa. Acta Paulista de Enfermagem, 20(2), v-vi. https://dx.doi.org/10.1590/S010321002007000200001.

Silva, A.M.M. (2008). A Lei sobre Guarda Compartilhada (2a ed). São Paulo: Leme J.H Mizuno.

Silva, E. L. (2005). Guarda de filhos: aspectos psicológicos. In Associação de pais e mães separados (Org.). Guarda compartilhada: aspectos psicológicos e jurídicos (pp.13-32). Porto Alegre: Equilíbrio.

Silva, D.M.P. (2011). Mediação e guarda compartilhada: conquistas para a família. Curitiba: Juruá.

Simão, R. B. C. (2005). O abuso de direito no exercício do poder familiar. In Associação de pais e mães separados (Org.). Guarda compartilhada: aspectos psicológicos e jurídicos (pp. 33-52). Porto Alegre: Equilíbrio. 
Simmel, G. (1989). Philosophie de la modernité: la femme, la ville, I'individualisme. Saint-Armand-Montrond, França: Éditions Payot.

Soares, C., \& Sabola, A, L. (2007). Tempo, trabalho e afazeres domésticos: um estudo com base nos dados da pesquisa nacional por amostra de domicílios de 2001 e 2005. Rio de Janeiro: IBGE, Coordenação de População e Indicadores Sociais. Recuperado de https://ww2.ibge.gov.br/home/estatistica/populacao/tempo trabalho afdo m pnad2001 2005.pdf

SOS Papá. (2018). Tenencia. Recuperado de http://www.sospapa.com/juridicos tenencia.html

SOS Papai. (2018). Recuperado de http://www.sos-papai.org/br index.html

Sottomayor, M.C. (2014). Regulação do exercício das responsabilidades parentais nos casos de divórcio. Coimbra: Almedina.

Sousa, L. P., \& Guedes, D. R. (2016). A desigual divisão sexual do trabalho: um olhar sobre a última década. Estudos avançados, 30(87), 123-139. http://dx.doi.org/10.1590/S0103-40142016.30870008.

Todo por nuestros hijos. (2014). Quienes somos? Recuperado de https://www.todopornuestroshijos.com.uy/quienes-somos-/

Vogel, M., \& Verjus, A. (2016). Le droit des pères à faire famille: des mobilisations pour des droits nouveaux... sans obligation nouvelle. In A. Martial, Des pères "en solitaire": ruptures conjugales et paternité contemporaine (pp.139-151). Aix-Marseille, França: Presses Universitaires de Provence. 
Sobre os autores

Carolina de Campos Borges é doutora em Psicologia pela Pontifícia Universidade Católica do Rio de Janeiro (PUC-Rio), com pós-doutorado na Université Nouvelle Sorbonne (Paris 3) e no Programa de Psicologia Social da Universidade do Estado do Rio de Janeiro (UERJ). Atualmente é professora Adjunta na Universidade Federal da Grande Dourados (UFGD). E-mail: carolinacambor@gmail.com Anna Paula Uziel é doutora em Ciências Sociais pela Universidade Estadual de Campinas (UNICAMP), Professora Associada na Universidade do Estado do Rio de Janeiro (UERJ). Email: uzielap@gmail.com

Edna Lúcia Tinoco Ponciano é doutora em Psicologia Clínica pela Pontifícia Universidade Católica do Rio de Janeiro (PUC-Rio). Professora Adjunta na Universidade do Estado do Rio de Janeiro (UERJ). E-mail:

ednaponciano@uol.com.br

A contribuição de cada autor pode ser atribuída como se segue: Carolina de Campos Borges foi responsável pela pesquisa, análise dos resultados e redação do artigo. Anna Paula Uziel contribuiu no processo de interpretação dos resultados e redação do artigo. Edna Lúcia Tinoco Ponciano contribuiu com a redação e revisão do artigo.

Os autores agradecem à Dra. Alejandra Lópes Gómes, professora titular da Universidad de la República, pela viabilização da realização da pesquisa no Uruguai; e à Dra. Beatriz Ramos, professora titular de direito de família e sucessões da Universidad Católica del Uruguay, pelos esclarecimentos sobre os aspectos jurídicos da guarda compartilhada no Uruguai.

Recebido em: 23/06/2019

Revisado em: 12/08/2019

Aceito em: 16/12/2019 